\title{
Participação social no contexto $d a$ Atenção Primária em Saúde: um estudo de caso das Comissões Locais de Saúde do SUS de Belo Horizonte
}

| ${ }^{1}$ Ana Maria Caldeira Oliveira, ${ }^{2}$ Sueli Gandolfi Dallari |

Resumo: O objetivo do estudo é analisar as

Comissões Locais de Saúde (CLS) do Sistema

Único de Saúde de Belo Horizonte (SUS-BH) como

espaços de ampliação da democracia à luz da Teoria

Democrática Deliberativa. A pesquisa foi realizada no

1 Faculdade de Saúde Pública, Universidade de São Paulo.

São Paulo-SP, Brasil. Endereço

eletrônico: amcoliveira@usp.br

período de outubro/2013 a junho/2014 com análise de três CLS. Utilizou-se a técnica de observação participante com a adoção de um diário de campo. Como resultado do processo democrático, ainda que de maneira tímida e desorganizada, destacase o fluxo de informações horizontal, que através das discussões permite acompanhar e fiscalizar as políticas públicas, indo além do setor saúde, visando à redução das iniquidades sociais. Ao discutirem sobre temas que afetam suas vidas e decidirem por meio de acordos, as CLS revelam-se como espaços públicos verdadeiramente democráticos, de ampliação da democracia.

> Palavras-chave: participação social; atenção primária à saúde; democracia. 
O golpe que instaurou a ditadura militar no Brasil acaba de completar 50 anos. O jornal Folha de S. Paulo (MENDONÇA, 2014), em meio às reflexōes sobre esse período, publicou uma pesquisa realizada no país, na qual $62 \%$ dos entrevistados afirmaram que a democracia é sempre melhor que qualquer outra forma de governo. Santos e Avritzer (2005) já haviam observado que a democracia assumiu lugar central no campo político durante o século XX. Dessa maneira, a democracia é o regime político mais valorizado no mundo contemporâneo, sendo adotado pela quase totalidade dos países como regime político oficial (BISPO JÚNIOR; GERSCHMAN, 2013).

Entretanto, democracia possui sentido polissêmico, e Nobre (2004) ressalta a existência de uma disputa política sobre seus sentidos. Essa disputa estaria delimitada a duas grandes arenas. A primeira seria em torno de macroestruturas que definiriam o quadro institucional de um regime democrático: eleiçôes periódicas e livres, separação de poderes, regime de governo, respeito a direitos e garantias individuais. Uma segunda arena diz respeito à criação de novos espaços de participação e deliberação, que desafiam as macroestruturas do regime democrático, tanto no sentido de desafiar sua capacidade de abrigar essas novas formas de participação, como, em algumas ocasiōes, colocar em dúvida a lógica do arranjo macroestrutural em vigor (NOBRE, 2004).

Wampler (2010) vê a gestão participativa no Brasil como possibilidade de novas formas de intermediação entre Estado e sociedade civil, compensando a fragilidade dos outros mecanismos de interação Estado-sociedade. Segundo o autor, o Poder Legislativo seria um caminho natural por meio do qual os cidadãos e líderes comunitários poderiam pressionar as autoridades do governo, mas, devido a sua "debilidade institucional" (WAMPLER, 2010, p. 396), isso acaba não ocorrendo. Por sua vez, os partidos políticos, via clássica para cidadãos e lideranças aportarem suas demandas, oferecem poucas oportunidades, devido a um sistema partidário fragmentado e com baixa identificação entre os eleitores. Além disso, percebe-se uma subordinação do Poder Legislativo ao Poder Executivo (WAMPLER, 2010). Não é à toa que apenas $9 \%$ dos entrevistados da pesquisa da Folha de S. Paulo (MENDONÇA, 2014) afirmaram estar muito satisfeitos com o funcionamento da democracia no país. 
Nesse cenário em que se apresentam dificuldades para a consolidação das dimensões formais e estruturais da democracia representativa, permeiam os novos mecanismos participativos, buscando promover maior envolvimento dos cidadãos, maior transparência e um fluxo de informaçôes mais amplo e horizontal nas decisões sobre as políticas públicas (COELHO et al., 2010). Nas ultimas décadas, o Brasil tornou-se referência para o debate internacional acerca do aprofundamento da democracia em função das experiências participativas, especialmente, os Conselhos Gestores e o Orçamento Participativo (BISPO JÚNIOR; GERSCHMAN, 2013).

\section{Espaços de ampliação da democracia}

Carvalho (1997, p. 93) ressalta como um dos "feitos mais notáveis" da Reforma Sanitária brasileira a institucionalização dos Conselhos de Saúde. A agenda da Reforma Sanitária, por meio das propostas participativas, preocupava-se com os mecanismos de funcionamento do Estado e não apenas com os resultados redistributivos de suas políticas. Assim, o mote "Saúde é democracia e Democracia é saúde" visava também à reforma da política, de maneira que o direito à saúde fosse acompanhado pelo direito à participação no poder. Com efeito, a Constituição Federal de 1988 (BRASIL, 1988) concretizou os princípios que regem a participação da sociedade na formulação de estratégias e no controle da execução da política de saúde (BRASIL, 1990).

Em Belo Horizonte (BH), a Lei Municipal no 5.903 de 1991 (BELO HORIZONTE, 1991) institucionalizou o Conselho Municipal de Saúde (CMSBH), os Conselhos Distritais de Saúde (CDS) e as Comissões Locais de Saúde (CLS). Desse modo, verifica-se a existência de um Sistema Municipal de Participação Social em Saúde, constituído pelo Conselho Municipal, por nove Conselhos Distritais (um em cada distrito sanitário) e por 147 CLS, localizadas nas Unidades Básicas de Saúde (UBS), evidenciando a institucionalização generalizada dos espaços participativos (WAMPLER, 2010), a partir de um amplo processo de descentralização. Esse sistema estabelece uma conexão do nível local, ou intramunicipal (COELHO, 2011), ao municipal.

No município, a Atenção Primária à Saúde (APS) é composta pela rede de Unidades Básicas de Saúde, sendo organizada a partir da definição de territórios sobre os quais as UBS devem ter responsabilidade sanitária (BELO HORIZONTE, 2008). Tem entre seus princípios a universalidade, a acessibilidade, a coordenação 
do cuidado, o vínculo, a integralidade, a humanização e a participação da sociedade (BRASIL/MS, 2006a). Dessa maneira, as CLS constituem espaços participativos do Sistema Único de Saúde (SUS-BH) mais próximos da população, devendo propor, acompanhar e fiscalizar a implementação de políticas (BELO HORIZONTE, 1991).

Ao refletirem sobre os Conselhos de Saúde, do ponto de vista da ampliação da democracia, Bispo Júnior e Gerschman (2013) destacam o formato de composição dos conselhos, ou seja, a paridade entre os representantes dos usuários e os demais segmentos e o caráter deliberativo. Todavia, os parâmetros destacados parecem ser insuficientes para a análise dos Conselhos Gestores das UBS. As CLS, assim como as UBS, precisam afirmar-se como porta de entrada preferencial da população, para a participação e para os serviços de saúde (BRASIL/MS, 2006b), respectivamente. Desse modo, a inclusão de novos atores sociais, por meio do envolvimento das comunidades, estaria sujeito ao princípio da paridade? Em relação ao caráter deliberativo, a Lei no 8.142 (BRASIL, 1990), que atribui aos conselhos o poder deliberativo, não esclarece o que seja deliberar. Deliberar é a decisão em si? Deliberar é o processo de formação da vontade geral que leva à decisão?

Nesse contexto, o trabalho aqui apresentado pactua com a tendência verificada nos estudos empíricos, na área de participação, de analisar a efetividade participativa pelos resultados (COELHO, 2011; AVRITZER, 2011). Bispo Júnior e Gerschman (2013) concordam que a ampliação da democracia fundamenta-se, principalmente, nos resultados do processo democrático. O objetivo do estudo é analisar as Comissóes Locais de Saúde do SUS-BH como espaços de ampliação da democracia à luz da Teoria Democrática Deliberativa.

\section{Metodologia}

Trata-se de estudo empírico descritivo com adoção de metodologia qualitativa. Um estudo de caso único envolvendo mais de uma unidade de análise (YIN, 2010). A seleção das unidades de análise foi realizada a partir de um convite, feito aos Conselhos Distritais, para participarem da pesquisa, indicando sua Comissão Local de Saúde mais atuante. Os Conselhos Distritais Leste e CentroSul responderam prontamente ao convite. As CLS indicadas possuem Índice de Vulnerabilidade Social (IVS) opostos (BELO HORIZONTE, 2008): muito elevado risco e baixo risco. O IVS, criado pela Secretaria Municipal de Saúde (SMSA) associa indicadores de base populacional, tais como moradia e renda, 
com indicadores da saúde, como mortalidade infantil, estratificando a população em baixo, médio, elevado e muito elevado risco. Para compor a pesquisa, foi selecionada uma Comissão Local com IVS de muito elevado risco, pertencente ao distrito sanitário Centro-Sul (quadro 1).

Quadro 1. Características das Comissões Locais de Saúde Analisadas. Belo HorizonteMG, 2014

\begin{tabular}{|c|c|c|c|c|}
\hline $\begin{array}{c}\text { Indicação } \\
\text { do Conselho } \\
\text { Distrital }\end{array}$ & $\begin{array}{c}\text { Comissóes } \\
\text { Locais de } \\
\text { Saúde }\end{array}$ & $\begin{array}{c}\text { Regional/ } \\
\text { Distrito } \\
\text { Sanitário }\end{array}$ & $\begin{array}{c}\text { Risco } \\
\text { Predominante } \\
\text { (IVS) }\end{array}$ & $\begin{array}{c}\text { Base Legal; } \\
\text { Instrumento } \\
\text { Normativo }\end{array}$ \\
\hline sim & $\boldsymbol{A}$ & Centro-Sul & Baixo Risco & LM 5.903/91 - Estatuto \\
\hline $\operatorname{sim}$ & $\boldsymbol{B}$ & Centro-Sul & M. Elevado Risco & LM 5.903/91 - Estatuto \\
\hline & Leste & M. Elevado Risco & $\begin{array}{c}\text { LM 5.903/91 - } \\
\text { Regimento Interno }\end{array}$ \\
\hline
\end{tabular}

A pesquisa de campo ocorreu entre os meses de outubro de 2013 a junho de 2014. Foi autorizada pelo Conselho Municipal de Saúde de Belo Horizonte, pelos Conselhos Distritais Leste e Centro-Sul e pelas CLS participantes da pesquisa.

Para descrição e análise da natureza participativa nas CLS, foi utilizada a técnica de observação participante, com a adoção de um Diário de Campo. A técnica de pesquisa documental foi empregada para a análise de documentos, sendo analisados os livros-ata e os regimentos internos das respectivas Comissóes Locais, além de outros documentos públicos.

\section{Resultados e discussão}

\section{Dinâmicas de participação e deliberação}

A institucionalização da participação, por meio da criação de instituições deliberativas, está condicionada ao desenho institucional, à existência de regras e normas que vinculam alguns fundamentos da Teoria Democrática com questôes práticas de funcionamento dessas instituições (FUNG, 2004; AVRITZER, 2011) como, por exemplo: inclusão, publicidade, igualdade deliberativa e pluralidade de composição. Nesse sentido, a Lei $n^{\circ}$ 5.903/91 (BELO HORIZONTE, 1991) normatizou o CMSBH como órgão colegiado, de caráter permanente e deliberativo. Já as CLS, de acordo com essa lei, terão sua organização e norma de funcionamento definidas em Regimento Interno próprio. 
Apesar de a lei estabelecer a adoção do instrumento normativo Regimento Interno, duas das três CLS analisadas possuem sua organização e norma de funcionamento estabelecidas em Estatuto. Essas comissões estão localizadas no mesmo distrito sanitário, o que explicaria um teor semelhante dos Estatutos, evidenciando a existência de uma padronização por distrito sanitário. Os Estatutos estabelecem como competência das CLS deliberar sobre problemas relativos a saúde e outros de interesse da comunidade. Já o Regimento Interno prevê que a Comissão Local de Saúde terá poder deliberativo e/ou decisório em relação aos problemas na área de abrangência da UBS.

A gente tem caráter deliberativo, a gente pode definir o que vai ser feito! (Diário de Campo, 5/06/2014).

Moreira e Escorel (2010) relatam que o entendimento hegemônico por parte dos Conselhos de Saúde é de que deliberar é o resultado da votação realizada em plenário, que se concretiza em um documento oficial, de caráter normativo, devendo ser homologado pelos governantes. Nas Comissões Locais analisadas, o resultado das discussões e decisões é fruto de acordos consagrados sem a realização de votaçōes. Além disso, essas decisōes são registradas em livro-ata, não existindo um documento, uma resolução a ser homologada pelo prefeito. Dessa maneira, corre-se o risco de se chegar à conclusão de que as CLS não são deliberativas.

Todavia, Habermas (1989) ressalta a importância da esfera pública para orientar e controlar a qualidade do processo de tomada de decisão por meio de discussões entre cidadãos. Os participantes devem defender seus pontos de vista levando a uma transformação argumentativa de opiniōes, constituindo um agir comunicativo. Nobre (2004) aponta Cohen como o responsável por alterar os termos do debate democrático ao conceber a democracia deliberativa estruturada em torno de um ideal de justificação política, ou seja, justificar o exercício do poder político coletivo é proceder com base na argumentação pública. Assim se dá a passagem no interior da Teoria Democrática, de um conceito decisionístico de deliberação para um conceito argumentativo de deliberação (AVRITZER, 2000).

Os Estatutos estabelecem que qualquer pessoa residente na área de abrangência da UBS poderá fazer parte da Comissão Local, que terá a constituição mínima de seis membros efetivos e igual número de suplentes. A comissão será constituída por: dois membros de cada entidade representativa dos moradores e grupos da comunidade vinculados a UBS; dois membros representantes da UBS, eleitos pelos 
funcionários da unidade; e um terço dos membros da Comissão Local anterior, os quais estão livres de pertencerem, ou não, a entidades representativas. As reuniōes da comissão serão acompanhadas, obrigatoriamente, pelo gerente da UBS, que terá direito a voto. O Regimento Interno prevê, sem estabelecer um número mínimo ou máximo de participantes, a seguinte composição para a comissão: o gerente da UBS, membro nato; $50 \%$ de representantes da comunidade; $25 \%$ de trabalhadores e $25 \%$ de instituiçôes parceiras da comunidade.

Dessa maneira, constata-se que não existe um número predeterminado de conselheiros, ou mesmo uma preocupação com que as vagas sejam distribuídas respeitando-se o critério de paridade: $50 \%$ de usuários, $25 \%$ de trabalhadores de saúde e $25 \%$ de gestores e prestadores serviços (BRASIL/CNS, 2012). O que se observa é uma preocupação em assegurar a participação da comunidade, seja por meio de atores individuais e/ou coletivos.

Nós somos Comissão Local por sermos um grupo micro. (Diário de Campo, 5/06/2014).

Fung (2004, p. 176) denomina de "minipúblicos" esses espaços públicos de "escala modesta”, que reúnem cidadãos às dúzias e/ou às centenas. São espaços de encontros e atividades públicas, onde aqueles que dispõem de recursos, interesse e tempo participam. Segundo o autor, apesar de pequenos, esses espaços públicos estão entre os mais promissores para o engajamento cívico e a deliberação pública, por possibilitarem a accountability e justiça social.

Os Estatutos e o Regimento Interno das comissões estabelecem mandato de dois anos para os membros, reuniōes ordinárias mensais e extraordinárias quantas vezes forem necessárias. A reunião se realiza com a presença de maioria simples dos conselheiros e é aberta a todos que desejarem participar, tendo direito a voz. Os teóricos deliberativos destacam como verdadeiramente democrático a possibilidade de que todos se expressem no processo decisório, ainda que, em algum momento, seja realizada uma votação. Para eles, o processo de debate que precede o voto é que determina a legitimidade da decisão (ALMEIDA, 2010).

A convocação para as reuniōes ocorre, na maioria das vezes, 24 horas antes. As CLS não possuem estrutura administrativa própria ou mesmo um funcionário que fique responsável por escrever e encaminhar e-mails, pela elaboração de avisos e/ou cartazes divulgando e convocando para as reuniōes. A convocação é feita por meio de contato telefônico, realizado por um conselheiro, ou pelo próprio gerente da UBS. 
Eu mesmo fui ligando... [o gerente falando sobre a convocação]. Se avisa com maior antecedência, as pessoas esquecem! (Diário de Campo, 5/06/2014).

Precisa divulgar! [a Comissão Local]. Hoje, graças a deus, as pessoas estão empregadas. A gente não tem mais a facilidade de trazer pessoas às 14:00 h, durante a semana. (Diário de Campo, 6/02/14).

As reuniōes das CLS locais iniciam-se com a apresentação da pauta, e em duas delas, é seguida por uma rodada de apresentaçóes dos presentes. As reunióes são conduzidas pelo gerente da UBS e na sua ausência, por um trabalhador da unidade, que nas três comissões acompanhadas é um assistente social. Tanto o gestor quanto o trabalhador da saúde têm uma atuação bem próxima de um facilitador, expondo o tema da pauta e, depois, guiando a conversa, dando voz àqueles que se manifestam e incentivando aqueles sem voz a encontrá-la (FUNG, 2004).

Geralmente, o presidente da associação de moradores é o primeiro a se manifestar, sendo acompanhado pelos agentes comunitários de saúde (ACS), que são trabalhadores da saúde e, também, moradores da comunidade da área de abrangência da UBS e, na sequência, por usuários. Em um ambiente de diálogo surgem histórias, o testemunho, o relato de experiências. Dryzek (2004) observa que essas formas de comunicação devem ser acolhidas por serem capazes de induzir à reflexão e/ou conectar a experiência individual ou de grupo com algum princípio geral. Fica evidente a força da integração social que se desenvolve nesse espaço público por meio da solidariedade social (HABERMAS, 1995).

Você tem todos os direitos garantidos pela Constituição, mas se você não lutar por eles, não os terá! (Diário de Campo, 27/02/14).

A ideia de comunidade é desenvolver junto. Eu quero muito mais pra nossa comunidade! (Diário de Campo, 27/02/14).

Os temas das pautas de discussão das CLS são propostos na última reunião anual, como parte de um balanço das ações realizadas. Os participantes são provocados pelos gerentes das UBS e em uma brainstorming vão surgindo as ideias: implantação de sede do Alcóolicos Anônimos no bairro; construção de uma pista de caminhada; a questão do lixo; retorno do funcionamento da rádio comunitária; divulgação do projeto antitabagismo; trabalhar a questão das drogas - crack; violência; construção da nova UBS, entre outros.

As pautas escolhidas pela comunidade, como dengue e violência, resultaram em reuniōes mais cheias. (Diário de Campo, 8/05/14). 
Todavia, não é elaborada uma programação relacionando a temática a ser debatida, fruto da brainstorming realizada, com as datas das reuniōes e, dessa forma, os temas levantados acabam esquecidos. A pauta das reuniōes é estabelecida, em regra, na reunião anterior, indicada pelo gerente que propõe um tema prioritário.

Deveríamos pegar firme! Talvez, fazer um cronograma. (Diário de Campo, 8/05/14).

Podíamos fazer convites com maior antecedência. Os convites poderiam trazer as pautas. (Diário de Campo, 6/02/14).

Os críticos desses fóruns poderiam observar um ambiente assimétrico, onde o gestor acaba sendo o maior responsável pela composição da agenda, pela condução e até mesmo pela convocação das reuniōes, ou seja, que os agentes estatais teriam poder excessivo. Entretanto, Côrtes (2009) ressalta que os atores estatais são decisivos na definição das condições de funcionamento dos conselhos. É exatamente isso que se verifica, o desenvolvimento da Comissão Local de Saúde está diretamente relacionado ao envolvimento do gerente da UBS com esse fórum.

Quando o gerente não participa é porque ele não está ativo na unidade. Se eu não estiver aqui, a comissão morre! (Diário de Campo, 8/05/14).

\section{Conteúdo dos debates}

Alguns autores (FUNG, 2004; COELHO, 2011; AVRITZER, 2011) avaliam os processos participativos a partir do seu potencial para identificar as demandas da população, informar sobre as políticas públicas e detectar a qualidade dos serviços públicos recebidos por ela. Dessa maneira, o quadro 2 apresenta os temas discutidos, referente ao período de realização da pesquisa. O mês de outubro foi dedicado à realização das Conferências Locais, etapa das Conferências Distritais e Municipal de Saúde, que aconteceram no mês de novembro, justificando a não realização das reuniōes nas Comissões Locais $A$ e $B$ nesse mês. No mês de dezembro, as CLS debateram um tema comum: o balanço das ações em 2013, entrando em recesso no mês seguinte. Nos meses de fevereiro, março e abril, foi possível verificar a semelhança das pautas debatidas, que passam pela demanda de construção de novas instalações para as UBS; informações sobre a campanha de vacinação contra o papilomavírus humano (HPV), política pública para a prevenção do câncer de colo do útero; e a questão do lixo, que vincula a qualidade da prestação de serviços públicos, a mobilização da população e a ocorrência do dengue. As reuniōes de maio, junho e julho foram prejudicadas pela greve dos servidores da saúde e pela realização da Copa do Mundo no país. 


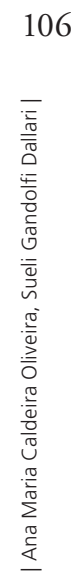

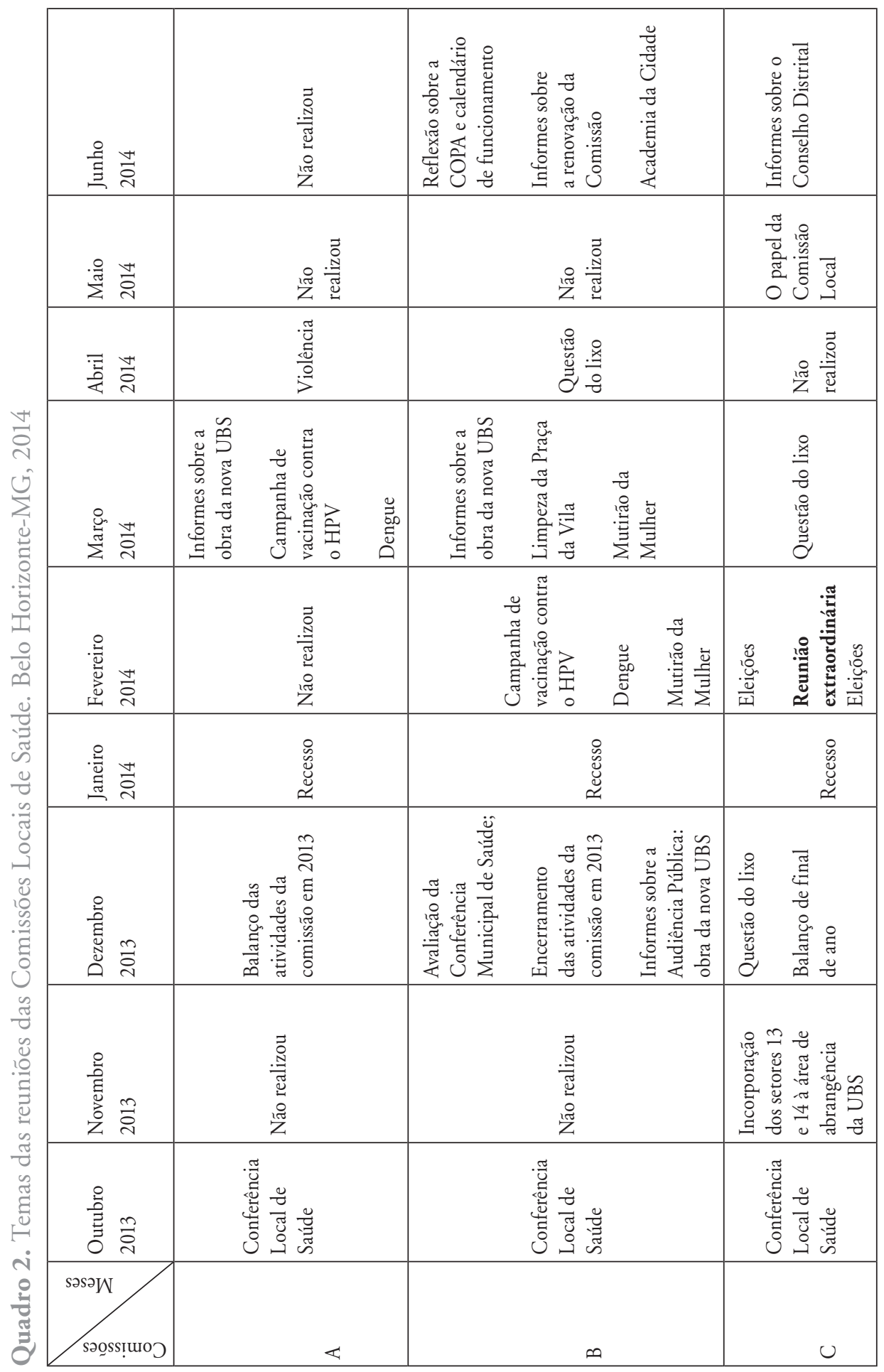




\section{A questão do lixo}

Em função de uma previsão catastrófica de ocorrência do dengue, a CLS C debateu a questão do lixo. Os agentes comunitários de endemias (ACE) alertaram aos participantes na reunião da comissão sobre a existência de armadilhas positivas, ou seja, armadilhas onde foram encontrados o mosquito do Aedes aegypt, e que indicam a possibilidade de ocorrer uma grande epidemia. Assim, o tema lixo é debatido associado ao tema "doenças".

A pessoa suja o meio ambiente e volta pra gente através das doenças. Prevenir as doenças é mais barato do que tratar. (Diário de Campo, 5/12/13).

O Projeto Verdinhos, em referência ao uniforme verde dos agentes comunitários de limpeza urbana da Superintendência de Limpeza Urbana (SLU-BH, 2013) é citado como uma boa iniciativa na limpeza da vila. Esse projeto propõe a coleta de lixo domiciliar nas vilas e favelas, porta a porta, com carrinho de mão, devido à urbanização irregular e à dificuldade de acesso a essas áreas. Entretanto, os participantes da Comissão Local anseiam por um maior envolvimento da SLU.

O projeto era pra ajudar a controlar o índice da dengue. Tem que limpar e educar. Hoje em dia só limpam. Tem campanha nas escolas? (Diário de Campo, 5/12/13).

Os participantes observam a necessidade de realizar uma forte campanha de mobilização. Segundo eles, existiria uma indiferença da SLU, além da falta de envolvimento e conscientização da própria comunidade. Os ACEs presentes na reunião relataram que possuem material para trabalhar com a comunidade, $\mathrm{e}$ admitiram também uma "relaxada" por parte da UBS: o último mutirão foi realizado há três anos, explicam.

Temos problemas com a falta de atenção dos órgãos públicos e o desleixo da comunidade. (Diário de Campo, 6/02/14).

Questôes como a falta de lixeiras, lixeiras pequenas, ausência de caminhão com porte adequado para trafegar na vila, descarte de material de botafora e necessidade de coleta diária, foram abordadas na discussão. Como encaminhamento, foi proposto o agendamento de nova reunião com a presença dos parceiros da comunidade para debater a questão do lixo: chamar alguém da Escola, do Centro de Referência de Assistência Social (CRAS), da SLU e do Projeto Providência.

Conscientizar a população é um processo! Trabalhar com a comunidade envolve todos nós: saúde, SLU, igreja, escolas. (Diário de Campo, 13/03/14). 

porcos, cachorros, cabritos e galinhas. No meu bairro passa todo o dia (o caminhão de lixo). Por que aqui também não pode passar todos os dias? É a classe social? (Diário de Campo, 5/12/13).

Avritzer (2000), ao analisar o pensamento de Habermas, destaca a visão da esfera pública como um espaço de interação face a face onde os indivíduos interagem uns com os outros, debatem as decisões tomadas pela autoridade política, o conteúdo moral das diferentes relaçoes existentes ao nível da sociedade e apresentam demandas em relação ao Estado. Por sua vez, Fung (2004, p. 180) observa como importante contribuição da esfera pública, "em uma cidade latinoamericana, poder facultar a um morador de favela dar-se conta de, e efetivamente avaliar seus interesses racionais em saneamento básico".

As CLS $A$ e $B$ debateram a questão do lixo e do dengue com argumentos muito semelhantes aos da Comissão Local $C$. Interessante observar que o Pacto pela Vida (BRASIL/MS, 2006a), componente do Pacto pela Saúde, é composto por um conjunto de compromissos sanitários e tem entre seus objetivos o fortalecimento da capacidade de resposta do SUS às doenças emergentes e endemias, entre elas o dengue. Dessa forma, ao debaterem a questão do lixo, as CLS atuam no acompanhamento e fiscalização da implementação de política pública.

\section{Violência}

O tema "violência" foi debatido nas três CLS sob o prisma de duas abordagens diferentes. $\mathrm{Na}$ Comissão Local $C$, o debate foi sobre a situação vivenciada pela comunidade, que sofre com o confronto de duas quadrilhas rivais, formadas por jovens ligados ao tráfico. Segundo registros em ata, a Polícia Militar, através do Grupamento Especial de Policiamento para Áreas de Risco (GEPAR), apreendeu 30 armas e efetuou a prisão de vários jovens. Como causas da violência foram elencados vários fatores: precariedade da educação, falta de atuação dos pais, perda dos valores da família, exclusão social e perda dos jovens para a droga.

O Programa de Controle de Homicídios Fica Vivo (MINAS GERAIS, 2003), com gestão da Secretaria Estadual de Defesa Social, atua em comunidades carentes com altos índices de homicídios e violência em geral e está presente na área de abrangência das Comissões Locais $B$ e $C$. O programa se estrutura em dois eixos de atuação: intervenção estratégica e proteção social. O eixo de intervenção estratégica, responsável pelo planejamento e coordenação de uma 
repressão qualificada, reúne os órgãos de Defesa Social, dentre os quais o GEPAR, o Poder Judiciário, o Ministério Público e a Prefeitura Municipal.

O eixo "proteção social" baseia-se em ações de atendimento aos jovens e trabalho em rede. Os atendimentos visam fomentar modos de vida diversos aos da criminalidade. Para o desenvolvimento do trabalho em rede, o programa busca interagir com a comunidade, construindo respostas para os problemas de cada região, reconhecendo os atores já existentes: assistência social, saúde, educação, etc. É uma visão social que percebe não só as necessidades, mas também as possibilidades e capacidades, que podem e devem ser desenvolvidas (BRASIL, 2004). Dessa forma, as CLS e o Fica Vivo (MINAS GERAIS, 2003) são parceiros na promoção da saúde e no combate à violência.

As Comissões Locais $A$ e $B$ debateram a situação de violência na comunidade e seus reflexos nas respectivas UBS. A Comissão Local $A$ discutiu os possíveis encaminhamentos para lidar com as ameaças recebidas por funcionários, em virtude da elaboração de um relatório para o Ministério Público Estadual, envolvendo usuário do SUS adscrito a UBS, que resultou em perda do poder familiar materno em função do uso de drogas.

A gente está em uma região difícil. Hoje cedo, ouvi tiros! (Diário de Campo, 09/06/14).

Já a Comissão Local $B$ tratou do contexto de violência combinado a um fluxo de atendimento aumentado, provocando várias situaçôes de agressōes morais. De acordo com a ata, o aumento da população a ser atendida prejudica o atendimento mais rápido, o que acaba gerando impaciência e falta de respeito dos usuários para com os profissionais de saúde. Os usuários presentes relataram a normalidade de um atraso no atendimento e que isso não justifica o desrespeito e a intolerância por parte dos usuários.

O espaço público que proporciona o debate face a face e permite a ventilação dos conflitos e tensóes (FUNG, 2004) através dos relatos dos trabalhadores agredidos frente aos representantes dos usuários é, sem dúvida, mais adequado à resolução de problemas da UBS do que a solução simplista de afixação de placas com advertência aos usuários do SUS, em caso de desacato a funcionário público. Importante ressaltar que Oliveira (2010) já havia associado o conflito existente entre os segmentos usuário e trabalhador no CMSBH com a tensão vivenciada por esses dois segmentos na ponta do SUS-BH, no cotidiano nas UBS, onde a demanda por 
serviços de saúde por parte dos usuários é sempre maior do que a possibilidade da prestação de serviços de assistência à saúde, ofertados pelos trabalhadores.

\section{Eleições}

Durante a realização da pesquisa, somente a Comissão Local $C$ debateu o tema "eleições" visando à renovação da comissão. A reunião da Comissão Local para a realização da eleição foi pré-agendada em dezembro, para ser realizada na primeira reunião anual, em fevereiro. Contudo, a reunião estava esvaziada: oito presentes. Coelho (2011) alerta que os gestores devem divulgar o processo eleitoral buscando maneiras de envolver os grupos menos organizados. Os participantes acordaram não realizar a eleição devido ao reduzido número de presentes, decidindo convocar uma reunião extraordinária, cabendo ao gerente da UBS a formalização dos convites por meio de uma convocatória.

Que pena, que às vezes, na nossa Comissão Local a comunidade não vem, as entidades não vêm. É importante espalhar que a Comissão Local não é do Centro de Saúde, não é dos trabalhadores, é da comunidade! Espalhem essa ideia! Diário de Campo, 27/02/14.

A comunidade é o principal ator! Se a comunidade não estiver interessada... dificilmente teremos êxito. (Diário de Campo, 13/03/14).

Entretanto, vale observar que o CMSBH estabeleceu que as eleições nos Conselhos Distritais e nas Comissões Locais devem ocorrer concomitantemente, no mês de julho. Assim, o CMSBH articula um processo de eleições uniforme, sob sua supervisão, mas garantindo aos Conselhos Distritais e as Comissões Locais a responsabilidade pela execução do seu respectivo processo eleitoral (OLIVEIRA et al., 2013) O processo de renovação das Comissões Locais deve ser organizado pelas comissóes, orientado pelo Regimento Interno e pelo Conselho Distrital. Dessa maneira, a realização de um processo eleitoral intempestivo expõe a falta de entrosamento entre a Comissão Local e o Conselho Distrital. Se por um lado a ausência de interação entre Comissão Local e o Conselho Distrital revela a perversidade do isolamento, por outro impede a sua contaminação.

Nosso conselho (distrital) está passando por um momento complexo, está sob intervenção do Ministério Público, virou palco de disputas pessoais. (Diário de Campo 5/06/14).

A reuniāo extraordinária é realizada no final do mês de fevereiro com 28 presentes. Não é composta uma chapa para disputar a eleição. Os nomes vão 
surgindo, indicados pelos presentes. A eleição acontece por aclamação. São

eleitos quatro conselheiros, com os respectivos suplentes. O tema "eleições" aparece novamente na reunião do mês de maio, que debateu o papel da Comissão Local, ficando acordado o acerto do calendário eleitoral com nova posse dos eleitos em julho.

\section{Rede de conexões}

As entidades parceiras da Comissão Local de Saúde $A$ são a Pastoral da Saúde da igreja Santo Inácio Loyola, creche Recanto do Menor, Obras Sociais Pavonianas - entidade filantrópica cristã, a Escola Estadual e o grupo de voluntárias. As reuniōes dessa Comissão Local são realizadas no espaço cedido pelas Obras Pavonianas. Vale destacar o forte relacionamento com entidades ligadas à Igreja Católica. Durante a pesquisa, estiveram presentes às reuniōes representantes da creche, da escola estadual e do grupo de voluntárias.

Já as Comissões Locais $B$ e $C$, localizadas em diferentes distritos sanitários, mas com o mesmo perfil (IVS muito elevado risco), possuem entidades parceiras semelhantes: o Programa Fica Vivo (SEDS-MG, 2003), o Centro de Referência de Assistência Social - CRAS (BRASIL, 2004), o Programa Mediação de Conflitos (BELO HORIZONTE, 2005) o Projeto Providência (ASSOCIAÇÃO PROJETO PROVIDÊNCIA, 1990), as Escolas Estaduais e as Igrejas Católicas e Evangélicas da comunidade.

Participam aqui na reunião pessoas de entidades que trabalham com a comunidade: Fica Vivo, Mediação de Conflitos, CRAS. A participação das entidades é muito importante! (Diário de Campo, 27/02/14).

Apesar de serem constantemente citadas nas reuniões das Comissões Locais $B$ e $C$, e de estarem presentes no território, o que se verifica é a ausência dessas entidades nas mesmas reuniões. Assim, constata-se a falta de comunicação entre as entidades e as Comissões Locais, não conseguindo articular a oferta de serviços e ações de proteção. É como se os parceiros não tivessem sido apresentados. Dessa forma, a rede de proteção social tecida pelo Estado, entidades filantrópicas e religiosas visando unir esforços contra as iniquidades sociais, nas áreas de vulnerabilidade e risco social, não se estabelece.

Chegou uma equipe nova! Precisamos interagir! Precisamos conhecer os parceiros! (Diário de Campo, 5/06/14). 


\section{Considerações finais}

Este estudo buscou analisar as Comissões Locais de Saúde do SUS-BH como espaços de ampliação da democracia. Todavia, tem-se a clareza que analisar três comissões, em um universo de 147, constitui uma limitação do estudo apresentado. Ainda assim, ao analisar as dimensões dinâmicas de participação e deliberação, conteúdo dos debates e redes de conexões, este artigo contribui para o conhecimento do modus operandi das CLS. Vale ressaltar que o estudo de espaços públicos participativos institucionalizados na Atenção Primária à Saúde ainda é uma linha de pesquisa incipiente. Dessa maneira, é importante desenvolver novos estudos sobre esses espaços participativos, por meio das dimensões aqui analisadas.

São espaços públicos ainda incipientes, com alto grau de informalidade e que enfrentam inúmeras dificuldades para se organizarem. Contudo possuem, ao mesmo tempo, a capacidade de reunir aqueles que serão afetados pelas políticas públicas, e consequentemente, são capazes de beneficiar não só os conselheiros, mas sobretudo os cidadãos das áreas de abrangência das Unidades Básicas de Saúde.

Como resultado do processo democrático, ainda que de maneira tímida e desorganizada, destaca-se o fluxo de informaçôes horizontal, que através das discussōes permite acompanhar e fiscalizar as políticas públicas, indo além do setor saúde, visando reduzir as iniquidades sociais. Nesse sentido, acerta a Reforma Sanitária ao preocupar-se em assegurar tanto o direito à saúde quanto o direito à participação no poder. Por isso, o SUS, através da APS, tem o dever de fomentar, seja por meio de divulgação, fornecimento de estrutura física e administrativa, mobilização e interação dos atores estatais, espaços públicos que possibilitem a integração social de populações tradicionalmente marginalizadas, objetivando não só o adensamento das redes locais e de suas conexões, mas também a conquista de serviços públicos de melhor qualidade e em tempo adequado.

Finalmente, deve-se observar que, apesar das dificuldades relatadas, esses fóruns, ao permitirem que todos se expressem no processo decisório, possibilitam o desenvolvimento de habilidades e arranjos democráticos pelos cidadãos. Ao discutirem temas que afetam suas vidas e decidirem por meio de acordos, destacam-se como espaços públicos verdadeiramente democráticos, de ampliação da democracia. ${ }^{1}$ 


\section{Referências}

ALMEIDA, D. R. Metamorfose da representação política: lições práticas dos conselhos municipais de saúde no Brasil. In: AVRITZER, L. (Org.). A dinâmica da participação local no Brasil. São Paulo: Cortez, 2010. p. 129-174.

ASSOCIAÇÃO PROJETO PROVIDÊNCIA. Projeto Providência. 1990. Disponível em: < http://arquidiocesebh.org.br/site/atuacao.php?menu=\%C3\%81rea\%20Social\&id=629 >. Acesso em: 26 jun. 2014.

AVRITZER, L. A qualidade da democracia e a questão da efetividade da participação: mapeando o debate. In: PIRES, R. R. C. (Org.). Efetividade das instituições participativas no Brasil: estratégias de avaliação. Brasília: IPEA, 2011. p. 13-24.

. Teoria democrática e deliberação pública. Lua Nova, São Paulo, v. 50, p. 25-46, 2000.

BELO HORIZONTE. Lei no 5.903, de 3 de junho de 1991. Cria o Conselho Municipal de Saúde de Belo Horizonte, a Conferência Municipal de Saúde, os Conselhos Distritais de Saúde, as Comissões Locais de Saúde e dá outras providências. Diário Oficial [do] Município, Belo Horizonte-MG, jun. 1991.

. Secretaria Municipal de Saúde. Sistema Único de Saúde: relatório de gestão 2007. 2008. Disponível em: < http://www.pbh.gov.br/smsa/arquivos/relatorio_de_gestao_ final_24-04-2008.pdf >. Acesso em: em 17 mai. 2014.

BISPO JÚNIOR, J. P.; GERSCHMAN, S. Potencial participativo e função deliberativa: um debate sobre a ampliação da democracia por meio dos conselhos de saúde. Cien Saude Colet, Rio de Janeiro, v. 18, n.1, p. 7-16, 2013.

BRASIL. Ministério da Saúde. Diretrizes operacionais dos Pactos pela Vida, em Defesa do SUS e de Gestão. 2006a. Disponível em: < http://www.saude.caop.mp.pr.gov.br/arquivos/File/ volume1.pdf >. Acesso em: 30 jun. 2014.

BRASIL. Ministério da Saúde. Conselho Nacional de Saúde. Resolução no 453, de 10 de maio de 2012. Aprova as seguintes diretrizes para instituição, reformulação, reestruturação e funcionamento dos Conselhos de Saúde. Diário Oficial [da] República Federativa do Brasil, Brasília-DF, mai. 2012.

Ministério da Saúde. Lei n 8.142, de 28 de dezembro de 1990. Dispóe sobre a participação da comunidade na gestão do SUS e sobre as transferências intergovernamentais de recursos financeiros na área da saúde dá outras providências. Diário Oficial [da] República Federativa do Brasil, Brasília-DF, 31 dez. 1990.

. Ministério da Saúde. Política Nacional de Atenção Básica. Brasília, DF: Ministério da Saúde, 2006b.

Ministério do Desenvolvimento Social e Combate à Fome. Sistema Único de Assistência Social. Politica Nacional de Assistência Social. Brasília, DF: Ministério do Desenvolvimento Social e Combate à Fome, 2004. 
BRASIL. Senado Federal. Constituição da República Federativa do Brasil. Brasília, DF: Senado Federal, 1988.

CARVALHO, A. I. Conselhos de saúde, responsabilidade pública e cidadania: a reforma sanitária como reforma do Estado. In: FLEURY, S. (Org.). Saúde e democracia: a luta do Cebes. Rio de Janeiro: Lemos editorial, 1997. p. 93-111.

COELHO, V. S. P. Uma metodologia para a análise comparativa de processos participativos: pluralidade, deliberação, redes e políticas de saúde. In: PIRES R. R. C. (Org.). Efetividade das instituiçôes participativas no Brasil: estratégias de avaliação. Brasília: IPEA, 2011. p. 279-95.

COELHO, V. S. P. et al. Mobilização e participação: um jogo de soma zero. Novos Estudos, São Paulo, v. 86, p. 121-139, 2010.

CÔRTES, S. M. V. Introdução: atores, mecanismos, e dinâmicas participativas. In: . (Org.). Participação e saúde no Brasil. Rio de Janeiro: Fiocruz, 2009. p. 19-39.

DRYZEK, J. S. Legitimidade e economia na democracia deliberativa. In: COELHO, V. S. P.; NOBRE, M. (Org.). Participação e deliberação: teoria democrática e experiências do Brasil contemporâneo. São Paulo: Editora 34, 2004. p. 41-62.

FUNG, A. Receitas para esferas públicas: oito desenhos institucionais e suas consequências. In: COELHO, V. S. P.; NOBRE, M. (Org.). Participação e deliberação: teoria democrática e experiências do Brasil contemporâneo. São Paulo: Editora 34, 2004. p. 173-209.

HABERMAS, J. Consciência moral e agir comunicativo. Rio de Janeiro: Tempo Brasileiro, 1989. . Três modelos normativos de democracia. Lua Nova, São Paulo, v. 36, p. 39-54, 1995.

MENDONÇA, R. Convicção na democracia é recorde, mostra pesquisa. Jornal Folha de $S$. Paulo, São Paulo, 30 mar. 2014. 30 A4.

MINAS GERAIS. Secretaria de Estado de Defesa Social. Programa de Controle de Homicídios Fica Vivo. 2003. Disponível em: < https://www.seds.mg.gov.br/index.php?option=com_co ntent\&task=view\&id=283\&Itemid=117 >. Acesso em: 16 jun. 2014 .

. Programa Mediação de Conflitos. 2005. Disponível em: < https://www.seds. mg.gov.br/index.php?option $=$ com_content $\&$ task=view $\&$ id $=285 \&$ Itemid $=119>$. Acesso em: 26 jun. 2014.

MOREIRA, M. R.; ESCOREL, S. Dilemas da participação social em saúde: reflexões sobre o caráter deliberativo dos conselhos de saúde. Saúde Debate, v. 84, n. 34, p. 47-55, 2010.

NOBRE, M. Participação e deliberação na teoria democrática: uma introdução. In: COElHO V. S. P.; NOBRE, M. (Org.). Participação e deliberação: teoria democrática e experiências do Brasil contemporâneo. São Paulo: Editora 34, 2004. p. 21-40.

OLIVEIRA, A. M. C. Vigilância sanitária, participação social e cidadania. 2010. 198 p. Dissertação (Mestrado em Saúde Pública). Faculdade de Saúde Pública, Universidade de São Paulo, São Paulo, 2010. 
OLIVEIRA, A. M. C.; IANNI A. M. Z.; DALLARI, S. G. Controle social no SUS: discurso, ação e reação. Cien Saude Colet. Rio de Janeiro, v. 18, n. 8, p. 329-38. 2013.

SANTOS, B. S.; AVRITZER, L. Introdução: para ampliar o cânone democrático. In: SANTOS, B. S. (Org.). Democratizar a democracia: os caminhos da democracia participativa. Rio de Janeiro: Civilização Brasileira, 2005. p. 39-82.

SUPERINTENDÊNCIA DE LIMPEZA URBANA DE BELO HORIZONTE. Agente Comunitário de Limpeza Urbana. 2013. Disponível em: <: http://portalpbh.pbh.gov.br/ $\mathrm{pbh} /$ ecp/comunidade.do? evento = portlet $\& \mathrm{pIdPlc}=$ ecpTaxonomiaMenuPortal \&app=slu \&t $\mathrm{ax}=22326 \&$ lang=pt_BR\&pg=5600\&taxp=0\& >. Acesso em: 17 mai. 2014.

YIN, R. K. Estudo de caso: planejamento e métodos. 4a ed. Porto Alegre: Bookman, 2010. WAMPLER, B. Transformando o Estado e a sociedade civil por meio da expansão das comunidades - política, associativa e de políticas públicas. In: AVRITZER L. (Org.). A dinâmica da participação local no Brasil. São Paulo: Cortez, 2010. p. 394-439.

\section{Nota}

${ }^{1}$ A.M.C. Oliveira participou da concepção, análise e interpretação dos dados e redação do artigo. S. G. Dallari participou da revisão crítica do conteúdo intelectual e aprovação final da versão a ser publicada. 
Social participation in the context of Primary Health Care: a case study of the Local Health Commissions in the Unified Health System in Belo Horizonte-MG, Brazil

This study aimed to analyze the Local Health Committees (LHC) of the Unified Health System of Belo Horizonte-MG, Brazil, as spaces for expansion of democracy in the light of Deliberative Democratic Theory. The survey was conducted from October 2013 to June 2014, with three CLS analysis. The technique of participant observation with the adoption of a field diary was used. As a result of the democratic process, although timid and disorganized, there is a horizontal flow of information, which through discussions allows one to track, monitor on public policy, going beyond the health sector, aimed at reducing social inequalities. When discussing about issues affecting their lives and decide by agreement, the CLS are truly democratic public spaces, for democracy expansion.

> Key words: social participation; primary health care; democracy. 